\title{
Facing uncertainty: An entrepreneurial view of the future? ${ }^{\dagger}$
}

\author{
Simon Bridge ${ }^{*}$ \\ Ulster University Business School, Belfast, Northern Ireland, UK \\ ${ }^{\star}$ Corresponding author. Email: simonbridge@btconnect.com
}

(Received 8 July 2018; revised 9 September 2018; accepted 12 September 2018; first published online 5 November 2018)

\begin{abstract}
In business the future is not predetermined, and the unexpected often happens. So how should entrepreneurs (and businesses) try to address that future uncertainty? This paper suggests that there are two main options:

1. The often-preferred approach seeks to reduce uncertainty by forecasting and planning, using 'leftbrained' logic and analysis.

2. The alternative way seeks to live with, and to benefit from, uncertainty by using ideas derived from exploration, effectuation, antifragility and 'trial and error'.

This paper compares the two approaches and considers their rationales and potential effectiveness. It suggests that forecasting and planning has many drawbacks and is often not the best way to operate in uncertain conditions. Nevertheless, it is often advocated and its thinking seems to have been adopted as the default philosophy for business. Therefore if, as has been suggested, uncertainty is the norm, do we need to advocate adopting a different way of thinking?
\end{abstract}

Keywords: uncertainty; prediction; forecasting; planning; exploring; antifragile

\section{Introduction: entrepreneurs and uncertainty}

Uncertainty is the normal state. You're nobody special. - Tom Stoppard, Rosencrantz and Guildenstern Are Dead, 1966

Most people in business would like to avoid uncertainty. They want to know what is going to happen - so they consult, or otherwise access, the views of a range of supposed experts such as market researchers, data analysts, economists and other gurus. Then they base their plans on what they have been told, trusting that they have thus removed the uncertainty they would otherwise face. But the reality is that in business, as in other areas of life, the future is not predetermined and apparently upsetting developments like Brexit, President Trump, and global warming do not change things from certainty to uncertainty: they just make the uncertainty more obvious.

We may not like this uncertainty, but preparing for it is an essential part of being an entrepreneur and/or running a successful business. Indeed, Cantillon (1755) introduced the term 'entrepreneur' into economic discourse as a label for someone who operated at risk - for instance committing to known expenditure in order to benefit from anticipated, but not guaranteed and essentially unknown, future returns. He offered the example of a farmer who leases land for an

\footnotetext{
${ }^{\dagger}$ This manuscript is an original work. It has not been published and is not being considered anywhere else.

(c) Cambridge University Press and Australian and New Zealand Academy of Management 2018.
} 
agreed rent but who does not know in advance what return he will get from the crops he hopes to grow on it.

Other definitions of an entrepreneur have subsequently been offered. For instance, the Oxford Handy Dictionary (1978) includes 'one who undertakes an enterprise, with chance of profit or loss' and Dictionary.com (2017) offers 'a person who organises and manages any enterprise, especially a business, usually with considerable initiative and risk'. Forbes (2012) suggests that the latter definition has got it right because 'entrepreneurs, in the purest sense, are those who identify a need - any need - and fill it'.

All these definitions imply that entrepreneurs have an anticipation of what the future will, or could, bring and base their actions on it. But how should entrepreneurs (and businesses) view the future: should they consider it to be largely predictable (as many people would like it to be) or as essentially uncertain and unknowable?

Deakins and Freel (2009: 6) explain that, where the outcome is certain (perfectly predictable), no opportunity for entrepreneurial profit exists - and instead the entrepreneur is someone who is prepared to undertake risk in an uncertain world. Knight (1921) made a distinction between risk and uncertainty. Risk, for him, is applied to situations where the outcome was uncertain but nevertheless could be predicted with a degree of probability which was known, or could be determined. An example given by Deakins and Freel is the risk of having your car stolen which can be calculated with some degree of probability and therefore it is possible to take out insurance against it, whereas true uncertainty is when the outcome is uncertain and the degree of risk cannot be assessed - so the risk cannot be transferred through insurance. And that is where entrepreneurs operate.

But how do, or should, entrepreneurs - and indeed all businesses - approach such situations? If they are not going to ignore the possible degree of risk and just proceed anyway, they need to make some sort of judgement about whether to proceed or not - and, if so, what should be the basis for their decisions? The instinctive way seems to be to try to forecast what the future will be and plan and make an investment decision on that basis. For instance, a farmer who assesses what he or she thinks the price for a crop will be when it is harvested and then, on that basis, makes an assessment of whether to invest in growing the crop. Such forecasts are often made on projections from current trends and, because a farmer generally needs to plan and do something, it seems to offer the best guidance. Of course, sometimes crops do fail so there is little to sell, or are so successful everywhere that prices fall, but over the longer term, farming has been sustainable.

Alternatively, when the offering is a new product or service, market research is carried out to provide an assessment of how the market would react as a basis for forecasting future sales. But, both for the farmer or the new product developer, whatever way the sales forecast is made, it can be used as the basis for a plan of action detailing the path the enterprise should take - and such plans have even been described as route maps to the desired or anticipated future (see Box 2). Indeed, much business wisdom still seems to assume that this procedure of making forecasts and then constructing and implementing plans based on them is the best, and therefore the recommended, way to proceed (Boxes 1-3).

However, Sarasvathy (2008) found that many successful entrepreneurs did not follow this wisdom. She researched 'expert' entrepreneurs who had taken a start-up to the stage of a public flotation, and found that they distrusted market research and didn't think that the future could reliably be forecast in this way. They appeared to understand that the future was not preordained and things could happen between now and them which could change it. So, it could not be reliably predicted but might instead be shaped. Therefore, Sarasvathy's entrepreneurs opted to approach the future with open minds prepared to react appropriately to what they found, rather than believing they could predict what would happen and then stick to preplanned routes come what may. She has labelled the former approach 'effectuation' - as opposed to the 'causation' approach of selecting the desired result and then trying to cause it to happen (see Box 4). 


\section{The purpose of this paper}

This suggests that essentially there are two schools of thought and/or approaches to the uncertainty of the future:

- The instinctive way, which is to try to reduce the degree of uncertainty by forecasting (and/ or attempting somehow to quantify the risk and/or thus reduce the uncertainty) and then making plans based on those forecasts - and this way seems to have become the received wisdom for business.

- However, there is an alternative way which accepts the uncertainty and involves being prepared to react accordingly and to try, not only to reduce any possible harm from the unexpected, but also to maximise its possible advantage.

But which is best and which should be advocated? The purpose of this paper is to explore these two approaches to the future - that of forecasting and planning and that of accepting uncertainty - to compare them and consider their effectiveness; and to recommend which, if either, should generally be followed.

\section{The appeal of forecasting and planning}

There is a fundamental paradox in human behaviour - the more unpredictable the world becomes, the more we seek out and rely on forecasts and predictions to determine what we should do (Gimpl and Dakin, 1984: 125).

Why is the forecasting and planning approach so popular? One reason seems to be that we have an instinctive aversion to uncertainty. According to Lotto 'Uncertainty is the problem that our brains evolved to solve'. We were, he suggests, afraid of uncertainty 'and for good reason - "not knowing" is an evolutionarily bad idea'. We wanted to know when there was danger and to respond accordingly because when humans were emerging in a world of dangerous beasts that way lay our survival:

'You didn't evolve to see reality - you evolved to survive' ... 'and seeing reality accurately isn't a prerequisite to survival. Indeed it could even be a barrier to it' (Lotto, 2017).

Possibly as a result of this, forecasting the future has a long pedigree, even if some of the methods used seem to us now lacking credible scientific support and even to be based essentially on superstition:

Foretelling the future has preoccupied man in every age. Prior to the twentieth century, the principal western methods of forecasting included astrology, ... palm reading and ... tarot cards. Minor techniques ranged from reading the entrails of slaughtered animals ... and reading cracks in roasted shoulder blades (Gimpl and Dakin, 1984: 126).

Because we want predictions in times of uncertainty, we want to believe in an ability to forecast. 'Superstitions increase in number and intensity as our environment becomes more uncontrollable and more unpredictable' (Gimpl and Dakin, 1984: 125) - and 'examples of our capacity for misplaced beliefs are not hard to find. If something seems plausible, impresses us, fits with what we'd like to think, or has been told to us persuasively, we are willing to treat it as the truth' (Graves, 2010: 1). And we don't take 'no' for an answer: where we don't feel we know enough to make a prediction we look for more information: 'people want more data to "solve problems"' (Taleb, 2013: 307).

Another key reason for the popularity of forecasting has been the concept of 'physical determinism' and the belief that, if we examine something sufficiently, we will be able to determine how it works so that, with enough information or data, we will be able to predict what it will do in the future (see Box 1). This belief has been seen as a promising source of predictions 
as it suggests that, with enough diligent effort, the mechanism behind any phenomenon can be explained and its future behaviour then predicted.

Box 1. - Clocks (and Clouds)

Popper (1973), the philosopher of science, suggested a division of systems and associated phenomena into two categories: clocks and clouds. Clocks, he suggested, 'represent physical systems which are regular, orderly, and highly predictable in their behaviour' whereas in contrast clouds 'like gasses, are highly irregular, disorderly, and more or less unpredictable'.

On the assumption that everything is essentially clock-like, a belief has developed that if we study something cleverly enough, we will be able to determine how it works and from that predict how it will behave in the future. This, Popper suggested, is a legacy of Newton:

'Newton's theory [of gravity] was the first really successful scientific theory in human history; and it was tremendously successful. Here was real knowledge; knowledge beyond the wildest dreams of even the boldest minds. Here was a theory which explained precisely not only the movements of all the stars in their course, but also, just as precisely, the movements of bodies on earth, such as falling apples, or projectiles, or pendulum clocks. And it even explained the tides.'

'All open-minded men - all those who were eager to learn, and who took an interest in the growth of knowledge - were converted to the new theory. Most open-minded men, and especially most scientists, thought that in the end it would explain everything, including not only electricity and magnetism, but also clouds, and even living organisms. Thus, physical determinism - the doctrine that all clouds are clocks - became the ruling faith among enlightened men; and everybody who did not embrace this new faith was held to be an obscurantist or a reactionary'.

Although Popper acknowledged that some things, like the motion of the planets examined by Newton, are very predictable, essentially he advocated a contrary view, and one which is compatible with quantum theory. 'I believe', he explained, 'that [...] all clocks are clouds, to some considerable degree - even the most precise of clocks' and that 'physical determinism is a nightmare [which] destroys, in particular, the idea of creativity'.

As Lehrer (2010) said, in commenting on Popper's analogy: 'The mistake of modern science is to pretend that everything is a clock [...] a neat orderly system that can be solved through reduction. [...] We want to believe we will understand nature if we find the exact right tool to cut its joints. But that approach is doomed to failure. We live in a universe not of clocks but of clouds.'

Although Newton's contribution to physics is often suggested as the basis for our belief in determinism, more recently physics itself has tended to abandon such ideas - in accordance with Heisenberg's Uncertainty Principle. However, in social science, it appears that a belief in determinism and thus the possibility of logical prediction still survives and practices which subscribe to this include economics and market research - both of which are used by businesses to help them to forecast the future.

It seems that the standard procedure when contemplating a new or modified consumer product is to conduct market research to assess the likely consumer response and the potential level of sales and then to make plans on the basis of those estimates. This is of course the basis for the 'business plans' which are frequently advocated as the essential, and logical, guide for all businesses including start-ups and which have become part of traditional (and big businessbased) business advice and teaching:

To start a business - you'll need a business plan (Invest NI, 2011)

It has become accepted that a carefully constructed business plan is important to the survival and successful performance of any business (Deakins and Freel, 2009: 316).

Writing a business plan is one of the most important tasks when starting up a new business (Barclays Bank, 2009). 
Box 2. - Business Plans: Can You 'Map' the Future?

Burns is just one author who has likened business plans to maps:

'The business plan is just like a road map and the planning process is just like map-reading: decide on where you are and the town you want to go to, and then you can start to plan your route' (Burns, 2011: 365).

'The business plan [...] is your final route map showing you what you need to do to launch and grow your new venture' (Burns, 2014: 15).

However, these quotes also indicate the fallacy of this approach. To have a route map, it is necessary to have a map of the possible routes from which you can select your desired path - but to produce a reliable map of the routes someone first has to explore the territory, survey it and establish routes through it. Yet the future is uncertain and unknown - and is thus unexplored and unmapped. As Mintzberg (1994: 229) put it:

'As we enter this discussion [...] it would be well to bear in mind the disarmingly simple point that "the future does not exist; how could there be knowledge about something non-existent"?'.

\section{The logic of accepting uncertainty}

The previous section indicates some of the reasons why a convenient, welcome and apparently evidence-based belief may have arisen that, with care and the appropriate methods, the future can reliably be forecast, as Newton was able to predict the motion of the planets - and those forecasts can then be used as the basis for planning. But others have doubted this and, for instance, Lotto, who is quoted above as suggesting that, as we evolved, reducing uncertainty was more important for survival than seeing reality accurately; nevertheless, also points out that reality matters and that:

Life is inherently uncertain because the world and things that constitute it are always changing. And the question of uncertainty will become an increasingly pressing issue in all parts of our lives. This is because, as we and our institutions become more interconnected, we become more interdependent. An increasingly more connected world is also inherently more unpredictable (Lotto, 2017: 9).

Forecasting and planning may be the conventional wisdom accepted and advocated by many business 'professionals' but it and/or its foundations are being criticised, at least in some quarters, and other approaches consistent with accepting uncertainty are suggested. These approaches amount to an alternative philosophy - and one which it is argued here is fundamental to successful entrepreneuring:

Entrepreneurship relates to ways in which people in all kinds of organisations behave in order to cope with and take advantage of uncertainty and complexity and how in turn this becomes embodied in: ways of doing things; ways of seeing things; ways of feeling things; ways of communicating things; and ways of learning things (Gibb, 2000: 16).

The forecasting and planning approach may be based on, or at least be supported by, a belief in 'physical determinism' (see Box 1), but Popper and others have attacked determinism from a number of perspectives. For instance:

- It is not consistent with current scientific understanding;

- Sarasvathy's entrepreneurs, mentioned earlier (and see Box 4), believed that the future is not preordained, as the clock theory suggests, but can instead be shaped by human action (Sarasvathy, 2008: 27).

- Some experienced market researchers admit that their methods do not work and that 'the findings obtained from most market research are completely unreliable' (Graves, 2010: dust jacket).

- History indicates that beliefs in the nature of things are often disproved by new events or discoveries. Taleb (2007) coined the term 'black swan' for the sort of unforeseen event 
which fundamentally confounds a previous belief about the nature of something (because the discovery of black swans in Australia confounded the previous belief that all swans were white).

So, if the future is indeed uncertain and cannot reliably be predicted, how can businesses operate successfully? A search though the literature reveals a number of methods, maxims and/or approaches which accept uncertainty and do appear to be mutually consistent and effective:

- Trial and error: Without experimentation little is gained and it is generally acknowledged that almost every successful innovation has been the product of 'trial and error' - although 'error' is really the wrong word because the process is effective and it is one of repeated trial, feedback and refinement. As Harford (2011) points out, trial and error is in many cases the only way to success. So, if things might fail, then it is better to fail early and learn from that failure.

- Minimising losses: One of the principles of 'effectuation' which Sarasvathy identified from the expert entrepreneurs she surveyed was that of 'affordable loss'. When faced with a new project 'this principle prescribes committing in advance to what one is willing to lose rather than investing in calculations about expected returns to the project' (Sarasvathy, 2008: 15) so they risked little and failed cheap. This approach was also identified by Taleb in the advice he passes on to ensure that the risk of catastrophe is zero: 'make sure that the probability of the unacceptable (i.e., the risk of ruin) is nil' (Taleb, 2013: 166).

- Antifragility: Antifragility means not just surviving uncertainty and upset but actually profiting from it. According to Taleb, who invented the word, the opposite of 'fragile' is not 'robust'. If something is fragile, he suggests, and it is handled roughly, it is likely to be damaged and if some something is robust it is likely to remain unaltered - but if something is antifragile it is likely to become stronger (Taleb, 2013).

- Lean start-up and design thinking: Antifragility is consistent with approaches such as lean start-up and design thinking, where it is recognised that good products are not generally good from the very start but become good from a process of refinement informed by empirical testing and market feedback. For instance, the concept of lean start-up (Ries, 2011) assumes that trying to make projections based on hypothetical questions about how people think they will respond to a product not yet available will not be meaningful and that the only way to get reliable feedback on a new offering is actually to offer real examples of it. Therefore, prototypes should be subject to real market testing as soon as possible so that their faults and imperfections can be identified early and subsequent versions improved. Of course, there is more to these techniques than just this, but essentially, they involve looking for such essential feedback and trying to get it as early and/or as cheaply as possible.

- Exploring: Advice such as this is also covered in the suggestion that new business ventures have much more in common with explorers that they do with larger established businesses - and therefore that they could benefit from learning how to explore as safely as possible instead of following established business teaching based essentially on big business practice. For instance, explorers know that, if the territory into which they are venturing is unexplored, then they cannot determine in advance exactly what they will find - and so should proceed accordingly. They should expect to find some false leads and dead ends, and should not put at risk more than they can afford to lose by committing everything on one possibility without having a way back (Bridge and Hegarty, 2013).

- Ready-fire-aim: Ready-aim-fire is an appropriate approach when firing a rifle at a target when, once the trigger is pulled; the marksman has no further control over the flight of the bullet. But when firing a guided missile, the appropriate approach is ready-fire-aim because, once it is fired, the missile can, and should, still be steered onto the target. Having the ability 
to steer a venture onto the target once it is launched is particularly helpful if the target is moving and that is much more like other real-life situations.

- 'Engineering' solutions: In the introduction to his book Engineers of Victory, Kennedy quotes Webster's definition of an engineer as 'a person who carries through an enterprise through skilful or artful contrivance' (Kennedy, 2014: xvi). The book is subtitled 'the problem solvers who turned the tide in the Second World War' and it describes how they did it, not by working out every move in advance, but by experimenting with a wide range of possible solutions, testing them to see which were promising and then building on success when they found it. That was how they 'engineered' victory, not by prior design, but by continuing invention, innovation, trial, observation and improvement.

- 'Right-brained' thinking: McGilchrist acknowledges that many early views about the two hemispheres of the brain are ill-founded and a travesty. Nevertheless, he argues that there are differences and that clock-like ideas of predictability are a product of 'left-brained' thinking upon which we now tend to rely too much, especially in the West. He has suggested that the left hemisphere of the brain likes things to be certain and predictable but it should be the servant, not the master, of the right hemisphere which instead seeks possibilities (McGilchrist, 2010 and see Box 3).

Perhaps this approach of accepting uncertainty is best summarised by Harford. He refers to an engineer in Tsarist Russia called Peter Palchinsky who in the early 20th century was sent to study coal mines in the Don basin but whose recommendations were too honest - so he was sent off to Siberia. Eventually pardoned he continued to offer advice to the Tsarist government and eventually also to the Soviet government but he continued to be honest and advise against prestige projects launched without adequate testing and feedback. Such advice continued to be unacceptable, so he was finally executed by Stalin's secret police - but the prestige projects, nevertheless, failed as he said they would (Harford, 2011: 21-26). The lesson Harford draws from this is that experience shows the value of 'trial and error' - and the dangers of shunning it and, like the Soviet empire, refusing to see that things might not be working and that there could be alternatives:

There are three essential steps to using the principles of adapting in business and everyday life, and they are in essence the Palchinsky principles. First, try new things, expecting that some will fail. Second, make failure survivable: create safe spaces for failure or move forward in small steps. As we saw with banks and cities, the trick here is finding the right scale in which to experiment: significant enough to make a difference, but not such a gamble that you're ruined if it fails. And third, make sure you know when you've failed, or you will never learn (Harford, 2011: 224).

\section{Comparing the approaches}

The two approaches outlined in the preceding sections are very different and involve difference concepts and perspectives. To illustrate this, Table 1 presents a brief comparison between them.

\section{Two tools}

Clearly, there are some situations in life where it is reasonable to rely on forecasts of the future. For some time to come winter will still follow autumn, tide tables are usually reliable and even short-term weather forecasts are becoming more accurate. Planning on the basis of such predictions will be a reasonable thing to do. However, there are many situations where the future is much less certain. Therefore, while this paper may be taken as indicating that the accept uncertainty approach often has many advantages, it does not suggest that one approach is universally better than the other - as both can have their uses. Determining which approach is 
Box 3. - The Divided Brain

McGilchrist acknowledges that 'the subject of [brain] hemisphere difference has a poor track record' and that many popular beliefs about it are 'a travesty' - but points out that, nevertheless, experts agree that there are differences. Based on experimental research, he argues that the left and right hemispheres of our brains have different insights, values and priorities. 'One way of looking at the difference would be to say that while the left hemisphere's raison d'être is to narrow things down to a certainty, the right hemisphere's is to open them up into possibility.

' Further, he suggests, left hemisphere thinking has become too dominant and, as a practical example of what he sees as us drifting ever more into the left hemisphere's version of the world, he offers the financial crash. 'It was fuelled by a belief that human behaviour can be confidently predicted by algorithms, whereas in fact we not only don't know - but in principle can never know - enough for this sort of prediction to be valid.'

Left hemisphere thinking suits a clock-like views (see Box 1) but it 'is manifestly not in touch with reality and, when it does not understand something, it simply makes up a story that makes sense in its own terms and tells it with conviction'. 'Because of its narrow focus and emphasis on getting certainty, the left hemisphere sees only bits and pieces, fragments which it attempts to put together to form a whole.' 'Machines give us the idea that the world is made from bits put together. At least in the so-called "life" sciences, we still imagine that things are mechanical, in just this way, while in physics the idea was discarded around a hundred years ago.'

In life, McGilchrist believes, we need both hemispheres. However, 'for practical purposes, narrowing things down to a certainty so that we can grasp them is more helpful - it is also illusory, since certainty itself is an illusion - albeit a useful one. Similarly the right hemisphere appreciates that all things change and flow, and are never fixed and static as the left hemisphere sees them. Nor are they isolated and atomistic (left hemisphere), but reciprocally interconnected (right hemisphere)'

(Source: Based on McGilchrist, 2010 and Rowson and McGilchrist, 2013).

Box 4. - Effectuation

Sarasvathy (2008) researched how 'expert' entrepreneurs actually operated. She interviewed 27 people who individually or in a team had founded one or more companies, had been involved in the running of such a company for 10 years or more and taken at least one of those companies public.

The first theme that emerged from interviewing them, she reported, was that 'expert entrepreneurs distrust market research' - they believed that the future was not preordained so, instead of using research to trying to predict it, these entrepreneurs felt they could shape it.

She recognised that they generally preferred what she called 'effectuation' as opposed to a 'causal' approach - with the difference being that a casual approach focussed on the desired end result and how to realise it, whereas effectuation involved seeing what could be done with the resources and means available.

Effectuation has its own logic, but it is not the logic of prediction. Sarasvathy distilled effectuation into five key principles:

1. The bird-in-hand principle: Start with the means that you have and create new effects with them.

2. The affordable loss principle: Don't put at risk more than you can afford to lose - so risk little and fail cheap.

3. The crazy quilt principle: Build alliances and partnerships with stakeholders as you proceed, not least as a way of spreading the risk.

4. The lemonade principle: Leverage surprise and exploit contingencies as and when they happen.

5. The pilot-in-the-plane principle: Causation seeks to predict the future, effectuation to control it. You are not dependent on an auto-pilot and can steer the venture as circumstances suggest.

appropriate depends on the situation for which they might be used - and therefore the wise venturer will learn about both of them and when to follow each. Sarasvathy herself, having identified causation and effectuation as alternative approaches, suggests that both should be taught. 'I do not teach effectuation as the only way to do entrepreneurship [and] instead the course is built around the notion of two toolboxes - causal and effectual - and how to use them.' 
Table 1. The approaches compared

\begin{tabular}{|c|c|c|}
\hline Approach & Forecast and plan & Accept uncertainty \\
\hline Concepts & $\begin{array}{l}\text { Research - followed by prediction } \\
\text { Decision-making and planning } \\
\text { 'Causation' } \\
\text { Working out the answer by logic } \\
\text { Assessing the chance of an acceptable outcome }\end{array}$ & $\begin{array}{l}\text { Trial and 'error' and lean start-up } \\
\text { Antifragility } \\
\text { 'Effectuation' and exploring } \\
\text { 'Engineering' results } \\
\text { Reducing the chance of an unacceptable outcome }\end{array}$ \\
\hline $\begin{array}{l}\text { Principles } \\
\text { and } \\
\text { methods }\end{array}$ & $\begin{array}{l}\text { Calculating the odds } \\
\text { Betting when the potential gains are attractive and } \\
\text { the odds are favourable } \\
\text { Then planning everything before starting }\end{array}$ & $\begin{array}{l}\text { Experimentation and testing } \\
\text { Betting when the possible losses are affordable } \\
\text { and the risk of the unacceptable is nil } \\
\text { Dealing with reality as it happens }\end{array}$ \\
\hline $\begin{array}{l}\text { Decision- } \\
\text { making } \\
\text { model }\end{array}$ & $\begin{array}{l}\text { Decisions are made based on maximising the } \\
\text { probability of an acceptable outcome - assessing } \\
\text { how likely it is to work (the chances of success) }\end{array}$ & $\begin{array}{l}\text { Decisions are made based on minimising the } \\
\text { probability of an unacceptable outcome - } \\
\text { assessing what might happen if it doesn't work } \\
\text { (the risk arising from failure) }\end{array}$ \\
\hline Philosophy & We can reliably forecast many things & The future is inherently uncertain \\
\hline $\begin{array}{l}\text { When to } \\
\text { use }\end{array}$ & $\begin{array}{l}\text { Use when the relevant future is sufficiently } \\
\text { predictable }\end{array}$ & Use when the future is essentially uncertain \\
\hline
\end{tabular}

(Sarasvathy, 2008: 231). Lave, in his foreword to Sarasvathy's book Effectuation, refers to the situation in which causal and effectual approaches might be suitable:

Causal problems are problems of decision; effectual problems are problems of design. Causal logics help us choose; effectual logics help us construct. Causal strategies are useful when the future is predictable, goals are clear, and the environment is independent of our actions; effectual strategies are useful when the future is unpredictable, goals are unclear and the environment is driven by human action. The causal actor begins with an effect he wants to create and asks, 'What should I do to achieve this particular effect?' The effectuator begins with her means and asks, 'What can I do with these means?' And then again, "What else can I do with them?" (Sarasvathy, 2008: xii).

\section{Choosing the less familiar tool}

In his foreword to Sarasvathy, Lave clearly indicates that in situations of uncertainty, 'when the future is unpredictable', effectuation is the better approach (Sarasvathy, 2008: xii), and those are the situations being considered in this paper. The first approach - forecasting and planning (causal) - appears to more instinctive, which might be why it has become the default approach which is generally advised and/or taught. But, for dealing with uncertainty, instinct and this instinctive approach are usually not appropriate - as the following comments suggest:

- 'Effectuators do not seek to avoid failure; they seek to make success happen. This entails a recognition that failure is an integral part of venturing well. Through their willingness to fail, effectuators create temporal portfolios of ventures whose successes and failures they manage - learning to outlive failures by keeping them small and killing them young, and cumulating successes through continual leveraging' (Sarasvathy, 2008: 17). As Taleb (2013: 181) points out, nature also 'fails early'.

- We suffer from 'Black Swan blindness: the underestimation of the role of the Black Swan' (Taleb, 2007: 307). In his book The Black Swan, Taleb uses the label 'Black Swans' for those events which are thought to be highly improbable and which are unexpected but which nevertheless do occur, often with very significant consequences. In effect he suggests that 
there are psychological biases which blind people to uncertainty - and which result in an underestimation of the possibility of the unexpected and in assessments of risk which exclude it.

- Instead, we have a bias towards predictions and seek them out and use them, even when they know that they are unreliable. 'Forecasting can be downright injurious to risktakers. [...] There are ample empirical findings to the effect that providing someone with a random numerical forecast increases his risk taking, even if the person knows the projections are random' (Taleb, 2013: 135). People want a route through the future that they can follow like a map (so they are attracted to business plans which are said to be 'route/ roadmaps' - see Box 2).

- Market researchers thought that 'if we just ask them people will tell us what they want, what they like and what they think. All we have to do then is do whatever they say.' [...] But 'market research is a pseudo science - in fact it's consumer.ology - and the beliefs underpinning it are false' (Graves, 2010: 1, 2). 'When market research wanders into the realm of the future it is inherently reckless' (Graves quoted by Woodward, 2011).

- 'Anthropologists and psychologists have long argued that magical rights and superstitious behaviour serve very important functions: they make the world seem more deterministic and give us confidence in our ability to cope' (Gimpl and Dakin, 1984: 125). 'Experts in the techniques of forecasting and planning perform the functions of magicians in primitive society. They provide a basis for a decision when there is no rational method' (Gimpl and Dakin, 1984: 130).

- 'Wisdom in decision making is vastly more important [...] than knowledge' (Taleb, 2013: 152). But following the accepted methods is a defence against accusations of wrong decision-making - which might arise if things do not go as predicted:

'Because adherence to standard procedures is difficult to second-guess, decision makers who expect to have their decisions scrutinized with hindsight are driven to bureaucratic solutions - and to extreme reluctance to take risks' (Kahneman, 2011: 204).

As Tim Dewey, who has held senior marketing positions in several blue-chip companies, put it, 'People use different stages of research so that if the initiative is unsuccessful they can say, "Look how thorough I was. I did my due diligence." In my experience it comes down to the organisational culture; where there's a fear of failure research is used to avoid getting the blame for a project that fails' (Graves, 2010: 3).

All this suggests that, in the situation of an unpredictable future, the apparent logic and/or evidence behind the 'forecasting and planning' approach is not as sound or as convincing as instinct might suggest and that the second approach of 'accepting uncertainty' is actually more realistic and produces better results. There are reservations about accepting uncertainty but these are largely the result of perceptions and biases rather than contrary evidence. For instance, it does not satisfy our clear desire for forecasts and predictions and it does not conform to traditional business theory and teaching - but these are not good reasons for rejecting it. The author has advocated this perspective to a number of enterprises and has generally met with a positive response - but it is too early, and the sample is too small for any form of definitive evaluation.

\section{A different philosophy}

Proponents of effectuation have observed that it is a tool which is appropriate for uncertainty whereas causation is a tool which can with advantage be used in situations when reliable forecasts can be made. Sometimes it is reasonable to look for predictions - but sometimes the future is uncertain and then always looking for predictions and not accepting uncertainty is foolhardy. 
Therefore, the sensible use of these tools will depend on knowing when forecasts can reliably be made - which in turns depends on an acceptance that sometimes the future will be uncertain.

However, accepting uncertainty and appropriate techniques, such as effectuation, require a different way of thinking. Not only do the two approaches outlined above involve difference concepts and perspectives but essentially they are based on different philosophies. Essentially, accepting uncertainty requires an acknowledgement that uncertainty is the norm, not the exception. Therefore, it is suggested that adopting an acceptable uncertainty approach is not like switching from one technique to another, but instead requires adoption of a different way of seeing things: a conscious abandonment of a constant search for certainty and instead an explorer's acceptance of the possibilities in uncertainty.

However, it would seem that there is still an underlying tendency to ignore the reality of uncertainty and, instead, to seek forecasts. A review of the literature suggests that the issue of uncertainty is rarely considered. According to Bylund and McCaffrey (2017: 462) 'current work presents an incomplete picture [...] by overlooking the importance of uncertainty' and Hodgson (2011: 170) comments on 'the decline of the Knight-Keynes concept of uncertainty in mainstream economics' which is 'due to a complex of factors, including the on-going fashion for models that purport to yield predictions'.

Indeed, where uncertainty is recognised, the main response to it appears to be to avoid it by prediction. For instance, Chandler, DeTienne, McKelvie, and Mumford, (2011: 388) talk about entrepreneurs needing 'to invent better ways to predict the future' and Welter and Kim (2018: 100) acknowledge that 'effectuation is the dominant decision-making strategy [but only] until the entrepreneur can predict the future with a very high degree of accuracy'.

An exception is Klir (2002: 6) when writing about the position of uncertainty in economics with particular reference to the work of George Shackle (1903-1992) for whom , Klir notes, 'decision making is inseparable from uncertainty' because in a predestinate world, decision would be illusory'. Also, in such a world, failure would be an indication of incompetence because it would inevitably suggest a lack of due diligence in planning - whereas in a situation of uncertainty the failure of one effort may be no more than an inevitable part of the trial and error necessary to establish what does work well. Therefore, ignoring uncertainty, and/or having a belief in the possibility of reliable prediction, magnifies the problem of 'failure' by giving it a false prominence as something always to be feared.

\section{Conclusion}

This review suggests that despite its apparent attractiveness, its instinctive appeal, its fit with conventional wisdom and its apparent credibility, forecasting and planning is usually not the best approach for addressing future uncertainty. Nevertheless, forecasting seems to be the basis for much business advice and teaching. Further, not only have its methods thus been advocated, but its philosophy also seems to have been adopted, whether consciously or sub-consciously, as the default view.

However, this paper suggests that, instead of trying to avoid uncertainty, we should seek to confront it. But, to do that, do we need to work out ways to inculcate a different philosophy and approach? Do we need a perspective which encourages us to consider, not how best to assess the odds and have a robust plan for the expected, but how to be antifragile so that, if the unexpected happens, as it will, we are ready to profit from it? That will not necessarily be easy - but doing what seems to be easy is unlikely to be productive.

Therefore, it is argued here, instead of trying to narrow things down to certainties by prior logical prediction and analysis, we need to be able, by different thinking, to open things up to the possibilities inherent in uncertainty by being more 'right-brained'. If we can do that then, instead of always choosing research, forecasts and plans, we might more often embrace approaches such as exploration, effectuation and antifragility. 


\section{References}

Barclays Bank (2009). A guide to writing a business plan, No. 004, July 2009 (www.barclays.co.uk/startupsupport. Accessed November 16, 2012.

Bridge, S., \& Hegarty, C. (2013). Beyond the business plan - 10 principles for new venture explorers. Basingstoke: Palgrave Macmillan.

Burns, P. (2011). Entrepreneurship and small business (3rd ed.). Basingstoke: Palgrave.

Burns, P. (2014). New venture creation. Basingstoke: Palgrave Macmillan.

Bylund, P. L., \& McCaffrey, M. (2017). A theory of entrepreneurship and institutional uncertainty. Journal of Business Venturing, 32(5), 461-475.

Cantillon, R. (1755). Essai sur la nature du commerce en général.

Chandler, G. N., DeTienne, D. R., McKelvie, A., \& Mumford, T. V. (2011). Causation and effectuation processes: A validation study. Journal of Business Venturing, 26(3), 375-390.

Deakins, D., \& Freel, M. (2009). Entrepreneurship and small firms (5th ed.). Maidenhead: McGraw Hill.

Dictionary.com (2017). Retrieved February 19, 2017 from www.dictionary.com.

Forbes (2012). Retrieved February 19, 2017 from http://www.forbes.com/sites/brettnelson/2012/06/05/the-real-definition-ofentrepreneur-and-why-it-matters/\#3c6f571871ae

Gibb, A. A. (2000). SME policy, academic research and the growth of ignorance, mythical concepts, myths, assumptions, rituals and confusions. International Small Business Journal, 18(3), 13-35.

Gimpl, M. L., \& Dakin, S. R. (1984). Management and magic. California Management Review, XXVII(1), $125-136$.

Graves, P. (2010). Consumerology. London: Nicholas Brealey Publishing.

Harford, T. (2011). Adapt: Why success always starts with failure. London: Little, Brown.

Hodgson, G. M. (2011). The eclipse of the uncertainty concept in mainstream economics. Journal of Economic Issues, XLV (1), 159-175.

Invest NI (2011). Advertisement on a hoarding at Belfast City Airport, October 2011.

Kahneman, D. (2011). Thinking fast and slow. London: Allen Lane.

Kennedy, P. (2014). Engineers of Victory. London: Penguin.

Klir, G. J. (2002). Uncertainty in economics: The heritage of G.L.S. Shackle. Fuzzy Economic Review, VII(2), 3-21.

Knight, F. H. (1921). Risk, uncertainty and profit. Boston, MA: Houghton Mifflin.

Lehrer, J. (2010). Breaking things down to particles blinds scientists to big picture. Wired (May 2010). Retrieved April 6, 2012 from www.wired.com/magazine/2010/04/st_essay_particles/

Lotto, B. (2017). Deviate: The science of seeing differently. London: Weidenfeld and Nicolson.

McGilchrist, I. (2010). The master and his emissary. New Haven and London: Yale University Press.

Mintzberg, H. (1994). The rise and fall of strategic planning. Hemel Hempstead: Prentice Hall.

Oxford Handy Dictionary (1978). Oxford: Oxford University Press.

Popper, K. (1973). 'Of clouds and clocks: An approach to the problem of rationality and the freedom of man'. In Objective Knowledge: An Evolutionary Approach.

Reis, E. (2011). The lean startup. London: Portfolio Penguin.

Rowson, J., \& McGilchrist, I. (2013). Divided brain, divided world. London: RSA.

Sarasvathy, S. (2008). Effectuation: Elements of entrepreneurial experience. Cheltenham: Edward Elgar.

Taleb, N. N. (2007). The Black Swan. London: Allen Lane.

Taleb, N. N. (2013). Antifragile: Things that gain from disorder. London: Penguin.

Welter, C., \& Kim, S. (2018). Effectuation under risk and uncertainty: A simulation model. Journal of Business Venturing, 33 (1), 100-116.

Woodward, D. (2011). 'Big ideas'. Director February 2011. Retrieved February 3, 2011 from www.director.co.uk

Biographical Note

Simon Bridge has Master's degree from Cambridge (Engineering) and the London Business School (Business Studies). After working in aeronautics and shipbuilding, Simon was the Enterprise Development Director of LEDU (the Northern Ireland Government's small business support agency) from 1984 to 1993 . He then ran his own business during which time he continued to explore enterprise and acted as a consultant and facilitator of enterprise and voluntary/ community sector development. Simon is currently a director of several voluntary/community sector organisations and is also a Visiting Professor at the Ulster University Business School.

Cite this article: Bridge S. 2021. Facing uncertainty: An entrepreneurial view of the future? Journal of $M$ anagement $\&$ Organization 27: 312-323. doi: 10.1017/jmo.2018.65 